\title{
HUBUNGAN PENGETAHUAN IBU BALITA DENGAN CAKUPAN STIMULASI DETEKSI INTERVENSI DINI (SDIDTK) ANAK BALITA DI WILAYAH KERJA PUSKESMAS JEMBATAN KECIL KOTA BENGKULU
}

\author{
The Relationship between Knowledge of Mother Toddler and Early Childhood Intervention \\ Stimulation Coverage in The Work Area of Jembatan Kecil Public Health Center
}

\author{
Dewi Aprilia Ningsih. I, Selpi Ara Bela \\ Program Studi Kebidanan STIKES Tri Mandiri Sakti Bengkulu \\ Email : dewiaprilianingsih.i@gmail.com
}

\begin{abstract}
This study aims to determine the relationship of knowledge of mothers under five with the Stimulation Coverage of Early Childhood Intervention Detection of Toddlers in the Work Area of the Jembatan Kecil Public Health Center in Bengkulu City. This research uses analytical survey method with cross sectional approach. The population in this study were all mothers who had children under five (1-5 years old) as many as 531 mothers of children under five. The sampling technique was carried out by simple random sampling obtained by a sample of 84 people. Data collection uses primary data by distributing questionnaires. Data analysis was performed by Chi-Square test and Contingency Coefficient test (C). The results showed: (1) of 84 people there were $50.0 \%$ of mothers who had less knowledge, $31.0 \%$ of mothers who had sufficient knowledge and $19.0 \%$ of mothers who had good knowledge; (2) out of 84 people there were $59.5 \%$ of people who did not do Early Childhood Intervention Detection Stimulation for Children and $40.5 \%$ of people who performed Early Childhood Intervention Detection Stimulation; (3) there is a significant relationship between maternal knowledge and the scope of the Early Childhood Intervention Detection Stimulation in the medium category.

Keywords : Mother's Knowledge, Stimulation Coverage of Early Childhood Intervention Detection
\end{abstract}

\begin{abstract}
Abstrak
Penelitian ini bertujuan untuk mengetahui Hubungan Pengetahuan Ibu Balita dengan Cakupan Stimulasi Deteksi Intervensi Dini Anak Balita di wilayah Kerja Puskesmas Jembatan Kecil Kota Bengkulu. Penelitian ini menggunakan metode survey analitik dengan pendekatan cross sectional. Populasi dalam penelitian ini adalah semua ibu yang memiliki anak balita (1-5 tahun) sebanyak 531 ibu balita. Teknik pengambilan sampel dilakukan secara simple random sampling diperoleh sampel sebesar 84 orang. Pengumpulan data menggunakan data primer dengan menyebarkan kuesioner. Analisis data dilakukan dengan uji Chi-Square dan uji Contingency Coefficient (C). Hasil penelitian didapatkan: (1) dari 84 orang terdapat $50,0 \%$ ibu yang memiliki pengetahuan kurang, $31,0 \%$ ibu yang memiliki pengetahuan cukup dan $19,0 \%$ ibu yang memiliki pengetahuan baik; (2) dari 84 orang terdapat $59,5 \%$ orang yang tidak melakukan SDIDTK dan $40,5 \%$ orang yang melakukan SDIDTK; (3) ada hubungan yang signifikan antara pengetahuan ibu dengan cakupan SDIDTK dengan kategori sedang.

Kata kunci : Pengetahuan Ibu, Stimulasi Deteksi Intervensi Dini
\end{abstract}




\section{PENDAHULUAN}

Salah satu indikator yang dapat menunjukkan tingkat kesejahteraan suatu negara dalam bidang kesehatan adalah angka kematian bayi. Semakin tinggi angka kematian bayi maka menunjukkan derajat kesehatan yang rendah, dan kurang efektifnya program kesehatan yang di terapkan. Oleh karena itu, menurunkan angka kematian bayi menjadi salah satu fokus banyak pihak termasuk pemerintah Indonesia (Pusat Data Profil Anak Indonesia, 2015).

Laporan SDKI kematian neonatus, bayi dan balita pada tahun 2012 menunjukkan angka terendah yaitu 19,32 dan 40 kematian per 100.000 kelahiran hidup.Tren data SDKI menunjukkan angka kematian neonatrum bayi dan balita yang cendrung menurun. Target pemerintah indonesia dalam RPJM 2015-2019 adalah untuk Angka Kematian Balita (AKB)dari 32 menjadi 24 kematian per 100.000 kelahiran hidup. (Pusat Data Profil Anak Indonesia, 2015).

Salah satu upaya untuk mendapatkan anak yang sehat dan cerdas adalah dengan melakukan upaya pemantauan pertumbuhan dan perkembangan balita atau dikenal dengan nama Stimulasi Deteksi Intervensi Dini (SDIDTK). SDIDTK merupakan revisi dari program Deteksi Dini Tumbuh Kembang (DDTK) yang telah dilakukan sejak tahun 1988 dan merupakan program pokok Puskesmas (Profil Kesehatan Indonesia, 2016).

Target SDIDTK pada tahun 2015 dimana target SDIDTK Balita 91\%, sementara capaian dari bulan Januari-Desember 2015 hanya 84\%. Apabila target cakupan SDIDTK di wilayah kerja Puskesmas tidak tercapai akan memberikan dampak pada status pertumbuhan dan perkembangan anak balita dan pra sekolah di wilayah tersebut tidak optimal (Kemenkes RI, 2015).

Tumbuh kembang mencakup dua peristiwa yang sifatnya berbeda tapi saling berkaitan dan sulit dipisahkan, yaitu pertumbuhan dan perkembangan. Pertumbuhan mempunyai dampak terhadap aspek fisik sedangkan perkembangan berkaitan dengan pematangan fungsi organ atau individu. Pada masa kanak-kanak merupakan fase yang sangat penting bagi perkembangan anak (Profil Kesehatan Indonesia, 2016).

Bila terdapat keterlambatan yang tidak diketahui sejak awal, maka perkembangan anak akan terganggu hingga dewasa nanti. Tujuan dari SDIDTK adalah untuk menilai perkembangan anak dalam empat faktor diantaranya penilaian sosial, motorik halus, bahasa dan motorik kasar dengan persyaratan tes yang telah ditentukan (Profil Kesehatan Indonesia, 2016).

Banyak faktor yang mempengaruhi ibu dalam kasus SDIDTK pada balita di puskesmas, diantaranya pendidikan, pengetahuan, motivasi, dan pekerjaan ibu. Pengetahuan ibu balita tentang SDIDTK akan berpengaruh terhadap pelaksanaan SDIDTK. Pengetahuan ibu balita yang baik tentang pentingnya SDIDTK akan berpengaruh terhadap partisipasi ibu untuk melakukan SDIDTK (Setiawan, 2014). Pengetahuan dapat menentukan tindakan seseorang dalam proses perubahan tingkah laku dan membuat keputusan lebih tepat, sehingga semakin baik tingkat pengetahuan ibu balita dalam tentang SDIDTK maka ibu balita tersebut cenderung akan melakukannya demi kesehatan dan kecerdasan anaknya untuk masa depan buah hatinya (Marmi dan Kukuh, 2015).

Profil Kesehatan Provinsi Bengkulu Tahun 2017 terdapat 175 Puskesmas yang melakukan SDIDTK. Jumlah balita 91.839 balita namun hanya 63,52 yang terdeteksi dengan cakupan tertinggi berada di Kota Bengkulu 6.895 dari 14851 balita yang ada atau (85\%) dan terendah di kabupaten Lebong hanya (30\%) atau 1.344 dari 2.381 balita yang ada. (Dinkes Provinsi Bengkulu, 2017). Profil kesehatan Kota Bengkulu Tahun 2017 terdapat 14.851 balita dan yang terdeteksi hanya $6.895(80 \%)$ balita, hal ini masih jauh berada di bawah target nasional yaitu (90\%). Di Kota Bengkulu terdapat 20 puskesmas dengan cakupan untuk DDTK/SDIDTK tahun 2017 dengan balita tertinggi berada di puskesmas Jembatan Kecil (84,2\%) dan terendah berada di puskesmas Jalan Gedang (76,9\%). (Dinkes Kota Bengkulu, 2017).

Menurut Data Puskesmas Jembatan Kecil yang memiliki wilayah kerja 3 Kelurahan yaitu kelurahan dusun besar, kelurahan panorama, kelurahan Jembatan Kecil dan terdapat 13 Posyandu. Pada februari sampai juli tahun 2017 terhitung 531 balita yang tercatat berada di wilayah kerja puskesmas ini dan yang di deteksi baru 136 balita atau kuraang dari setenganya (Puskesmas Jembatan Kecil, 2017). Berdasarkan uraian di atas, maka penulis tertarik untuk meneliti Hubungan Pengetahuan Ibu Balita dengan Cakupan Stimulasi Deteksi Intervensi Dini 
Anak Balita di wilayah kerja Puskesmas Jembatan Kecil Kota Bengkulu.

\section{BAHAN DAN METODE}

Penelitian ini menggunakan metode survey analitik dengan pendekatan cross sectional. Populasi populasi dalam penelitian ini adalah semua ibu yang memiliki anak balita (1-5 tahun) di wilayah kerja Puskesmas Jembatan Kecil Kota Bengkulu yang tercatat dalam posyandu dari bulan JanuariDesember Tahun 2017 sebanyak 531 ibu balita. Teknik pengambilan sampel dilakukan secara simple random sampling diperoleh sampel sebesar 84 orang. Pengumpulan data menggunakan data primer dengan menyebarkan kuesioner. Data yang digunakan dalam penelitian ini adalah data primer dan data sekunder. Data dianalisis menggunakan analisis univariat dan bivariate dengan uji Chi Square dan uji statistic Contingency Coefficient (CI).

\section{HASIL DAN PEMBAHASAN}

\section{Analisa Univariat}

Tabel 1. Distribusi Frekuensi Responden Berdasarkan Pengetahuan dan Cakupan SDIDTK di Wilayah Kerja Puskesmas Jembatan Kecil Kota Bengkulu

\begin{tabular}{lcc}
\hline Variabel & Frekuensi & Persentase \\
\hline Pengetahuan & & \\
Kurang & 42 & 50 \\
Cukup & 26 & 31 \\
Baik & 16 & 19 \\
Cakupan SDIDTK & & \\
Tidak dilakukan & 50 & 59,5 \\
Dilakukan & 34 & 40,5 \\
\hline Jumlah & $\mathbf{8 4}$ & $\mathbf{1 0 0}$ \\
\hline
\end{tabular}

Dari Tabel 1 di dapat bahwa menggambarkan bahwa dari 84 orang terdapat $50 \%$ ibu yang memiliki pengetahuan kurang, 31\% ibu yang memiliki pengetahuan cukup dan $19 \%$ ibu yang memiliki pengetahuan baik, serta dari 84 orang terdapat $59,5 \%$ orang yang tidak melakukan SDIDTK dan 40,5\% orang yang melakukan SDIDTK.

\section{Analisa Bivariat}

Analisa bivariat dilakukan untuk mengetahui hubungan masing-masing variabel yaitu antara variabel independen (pengetahuan) dengan variabel dependen (cakupan SDIDTK). Uji hubungan dilakukan dengan uji statistik chi-square sedangkan uji keeratan hubungan dilakukan dengan uji statistik koefisien kontingensi.

Tabel 2 menunjukkan dari 42 orang dengan pengetahuan kurang terdapat 34 orang yang tidak melakukan SDIDTK dan 8 orang melakukan SDIDTK, dari 26 orang dengan pengetahuan cukup terdapat 12 orang yang tidak melakukan SDIDTK dan 14 orang melakukan SDIDTK, dan dari 16 orang dengan pengetahuan baik terdapat 4 orang yang tidak melakukan SDIDTK dan 12 orang melakukan SDIDTK. Hasil uji statistik Pearson Chi Square $\mathrm{x}^{2}=$ 18,597 didapat $\mathrm{p}=0,000<0,05$ berarti signifikan, maka Ho ditolak dan Ha diterima. Berarti terdapat hubungan yang signifikan antara pengetahuan dengan cakupan SDIDTK di Wilayah Kerja Puskesmas Jembatan Kecil Kota Bengkulu. Hasil uji Contingency Coefficient didapat nilai $\mathrm{C}=0,419$ dengan nilai p (Approx.Sig) $=0,000<a=0,05$ berarti signifikan. Nilai $C=0,419$ tersebut dibandingkan dengan nilai $C_{\max }=0,707$ (karena nilai terendah dari baris atau kolom adalah 2). Karena nilai $C=0,419$ tidak jauh dengan nilai $\mathrm{Cmax}=0,707$ maka kategori hubungan sedang.

\section{Hubungan antara Pengetahuan ibu dengan SDIDTK di Wilayah Kerja Puskesmas Jembatan Kecil Kota Bengkulu \\ Berdasarkan hasil analisis bivariat pada tabel 2} menunjukkan bahwa dari 42 orang dengan pengetahuan kurang terdapat 34 orang yang tidak melakukan SDIDTK dikarenakan 12 orang ibu tidak tahu dan tidak mengerti, 16 orang tidak pernah mendapatkan informasi dari petugas kesehatan dan media massa, 1 orang tidak pernah datang keposyandu, 2 orang tidak pernah baca buku dan tidak tahu, 3 orang tidak mengetahui ada pemeriksaan SDIDTK. Dan 8 orang melakukan SDIDTK dikarenakan 2 orang tau dari tetangga, 2 orang diajak tetangga, 2 orang tahu dari teman, 1 orang tahu dari posyandu dan 1 orang tahu dari teman dan tetangga. Dari 26 orang dengan pengetahuan cukup terdapat 12 orang yang tidak melakukan SDIDTK dikarenakan 1 orang tidak bisa meninggalkan pekerjaan, 3 orang tidak memiliki waktu karena sibuk bekerja, 2 orang rumah jauh, 1 orang sibuk mengurus rumah tangga, 3 orang tidak tahu ada pemeriksaan, 1 orang tidak ada yang mengantar. Dan 14 orang melakukan SDIDTK dikarenakan 4 orang mendapatkan informasi dan 
Tabel 2. Hubungan antara Pengetahuan ibu dengan cakupan SDIDTK di Wilayah Kerja Puskesmas Jembatan Kecil Kota Bengkulu

\begin{tabular}{|c|c|c|c|c|c|c|c|c|c|}
\hline \multirow{3}{*}{ Pengetahuan } & \multicolumn{4}{|c|}{ Cakupan SDIDTK } & \multirow{2}{*}{\multicolumn{2}{|c|}{ Total }} & \multirow{3}{*}{$x^{2}$} & \multirow{3}{*}{$p$-value } & \multirow{3}{*}{ C } \\
\hline & \multicolumn{2}{|c|}{$\begin{array}{c}\text { Tidak } \\
\text { dilakukan }\end{array}$} & \multicolumn{2}{|c|}{ dilakukan } & & & & & \\
\hline & $f$ & $\%$ & $f$ & $\%$ & $f$ & $\%$ & & & \\
\hline Kurang & 34 & 81 & 8 & 19 & 42 & 100 & & & \\
\hline Cukup & 12 & 46,2 & 14 & 53,8 & 26 & 100 & 18,597 & 0,000 & 0,419 \\
\hline Baik & 4 & 25 & 12 & 75 & 16 & 100 & & & \\
\hline Total & 50 & 59,5 & 34 & 40,5 & 84 & 100 & & & \\
\hline
\end{tabular}

dari 16 orang dengan pengetahuan baik terdapat 4 orang yang tidak melakukan SDIDTK dikarenakan 1 orang banyak pekerjaan dan tidak bisa datang, 2 orang tidak ada transportasi dan tidak ada yang mengantar dan 1 orang jarak jauh dari rumah. Dan 12 orang melakukan SDIDTK dikarenakan ibu rajin datang keposyandu, sering membaca buku KIA dan internet, mendapatkan informasi dari petugas kesehatan dan dari teman.

Dari hasil kuesioner banyak responden salah menjawab pada pertanyaan nomor 12 yaitu apa saja yang harus dipantau dalam kegiatan SDIDTK. Banyak responden yang hanya mengetahui SDIDTK hanya untuk melihat pertumbuhan dan perkembangan anaknya seperti tinggi badan, berat badan dan anaknya normal atau tidak. Responden tidak mengetahui apa itu motorik kasar, motorik halus dan apa saja pemeriksaan yang dilakukan dalam SDIDTK. Hasil uji Chi-square (Continuity correction) ada hubungan yang signifikan antara pengetahuan dengan cakupan SDIDTK di Wilayah Kerja Puskesmas Jembatan Kecil.Dan hasil uji Contingency Coefficient didapatkan hubungan kategori sedang.

Hasil penelitian ini sejalan dengan penelitian Mariyana (2015) yang mengatakan bahwa ada hubungan yang bermakna antara pengetahuan ibu terhadap frekuensi pemeriksaan deteksi dini tumbuh kembang pada balita di Puskesmas sungai Jingah Banjarmasin tahun 2015. Pengetahuan sangat berpengaruh dengan frekuensi pemeriksaan deteksi dini tumbuh kembang. Sehingga, peningkatan pengetahuan perlu dilakukan dengan memperoleh informasi yang lebih banyak tentang pemeriksaan deteksi dini tumbuh kembang. Hal ini dapat diperoleh dari media massa atau penyuluhanpenyuluhan kesehatan. Hasil penelitian ini sejalan dengan penelitian Sari (2016) yang mengatakan bahwa ada hubungan yang bermakna antara pengetahuan dengan perilaku menstimulasi perkembangan anak usia 3-5 tahun. Hal ini dipengaruhi oleh faktor pendidikan, usia, pengalaman dan pekerjaan ibu.

Stimulasi merupakan hal yang sangat penting dalam tumbuh kembang anak. Anak yang mendapat stimulasi yang terarah dan teratur akan lebih cepat berkembang dibandingkan dengan anak yang kurang atau tidak mendapat stimulasi. Maka dari itu, pengetahuan tentang stimulasi tumbuh kembang, sangat penting bagi calon ibu yang sudah mempunyai anak (Kurniawati dkk, 2017).

Hasil penelitian ini sejalan dengan penelitian Fitriani (2017) yang mengatakan bahwa faktor yang menghambat Stimulasi Deteksi Intervensi Dini Anak Balita yaitu kurangnya dukungan sosial, social budaya, faktor ekonomi, rendahnya tingkat pendidikan serta kurangnya sarana dan prasarana yang tersedia membuat orang tua tidak melakukan SDIDTK pada anaknya.

Meskipun pengetahuan relatif baik, tetapi masih banyak ibu yang tidak melakukan SDIDTK terhadap balitanya dikarenakan masih ada beberapa ibu yang belum paham dan mengerti sepenuhnya tentang SDIDTK sehingga diharapkan pihak Puskesmas dapat memberikan penyuluhan dan juga informasi mengenai pentingnya melakukan SDIDTK agar ibu memiliki minat yang tinggi untuk melakukan pemeriksaan SDIDTK terhadap anaknya.

\section{KESIMPULAN DAN SARAN}

Berdasarkan hasil penelitian diperoleh bahwa Ada hubungan yang bermakna antara pengetahuan ibu dengan cakupan Stimulasi Deteksi Dini Tumbuh Kembang Anak Balita di Wilayah Puskesmas Jembatan Kecil. Diharapkan hasil penelitian ini dapat bermanfaat sebagai bahan masukan bagi pelaksana 
program Stimulasi Deteksi Intervensi Dini (SDIDTK), yaitu pihak Puskesmas agar dapat meningkatkan informasi dan minat ibu balita untuk melakukan SDIDTK pada anaknya dapat melalui penyuluhan, penyebaran leaflet, ataupun program jemput bola dengan bantuan kader di posyandu untuk memastikan bahwa ibu mau melakukan SDIDTK secara rutin terhadap balitanya dan semua balita telah mendapatkan pemeriksaan SDIDTK.

\section{DAFTAR PUSTAKA}

Dinkes kota Bengkulu, 2017. Profil Kesehatan Kota Bengkulu 2017. Bengkulu: Dinas Kesehatan Kota.

Dinkes Provinsi Bengkulu, 2017. Profil Kesehatan Provinsi Bengkulu 2017. Bengkulu: Dinas Kesehatan Provinsi.

Setiawan, Dony., 2014. Keperawatan Anak Dan Tumbuh Kembang (Pengkajian Dan Pengukuran). Yogyakarata: Nuha Medika.

Fitriani, Inna S dan Rona Riasma O., 2017. Stimulasi, Deteksi dan Intervensi Orang Tua Terhadap Pencegahan Penyimpangan Pertumbuhan dan Perkembangan Anak Balita. Jurnal IJHS Vol. 1 No. 1 Maret 2017 hal. 01-09.

Kurniawati, dkk., 2017. Hubungan Pengetahuan Ibu Tentang Stimulasi Tumbuh Kembang Balita
Dengan Perkembangan Balita Usia 12-36 Bulan Di Posyandu Kasih Ibu 7 Bunyu Urip Klego Boyolali Tahun 2014. Jurnal Akademi Kebidanan Mamba' ul ‘Ulum Surakarta.

Mariyana, 2015. Hubungan Antar Pengetahuan dan Sikap Ibu Terhadap Frekuensi Pemeriksaan Deteksi Dini Tumbuh Kembang Pada Balita Di Puskesmas Sungai Jingah Banjarmasin Tahun 2015. Jurnal Akademi Kebidanan Bunga Kalimantan.

Marmi dan Kukuh, R., 2015. Asuhan Neonatus, Bayi, Balita dan Anak Pra Sekolah. Yogyakarta: Pustaka Belajar.

Puskesmas Jembatan Kecil, 2017. Profil Puskesmas Jembatan Kecil. Bengkulu : Puskesmas Jembatan Kecil.

Pusat Data dan Informasi Kemenkes RI, 2015. Stimulasi Deteksi Dini Tumbuh Kembang Anak di Indonesia.

Pusat Data Profil Anak Indonesia. 2015. Stimulasi Deteksi Dini Tumbuh Kembang Anak di Indonesia.

Sari, Lusi Yunita., 2016. Hubungan Pengetahuan Ibu Dengan Perilaku Menstimulasi Perkembangan Anak Usia 3-5 Tahun di Posyandu Kamboja Dusun Kalongan Mlati Sleman. Naskah Publikasi. Yogyakarta: STIKES ‘AISYIYAH 